\title{
Have Changes in Treatment of Late-detected Developmental Dysplasia of the Hip During the Last Decades Led to Better Radiographic Outcome?
}

\author{
Terje Terjesen MD, PhD, Joachim Horn MD, PhD
}

Published online: 20 August 2015

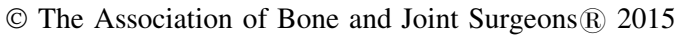

\begin{abstract}
Background Despite considerable changes in the treatment of of late-detected congenital or developmental hip dislocation (DDH) during the last 50 years, it is unclear whether and to what degree these changes have led to better long-term outcome for the patients.

Questions/purposes The aims of this study were to see whether decreasing use of skin traction and instead a more aggressive approach to open reduction resulted in (1) reduced use of secondary procedures; (2) improved radiographic appearance of the hips at long-term followup; and (3) changes in the proportion of patients developing avascular necrosis.

Methods Two groups of patients were compared retrospectively. Inclusion criteria were patient age older than 3 months and younger than 5 years at the initiation of treatment, no associated anomaly, no previous treatment in other hospitals, and available radiographs from the time of diagnosis to skeletal maturity. Group A consisted of 56
\end{abstract}

Each author certifies that he, or a member of his immediate family, has no funding or commercial associations (eg, consultancies, stock ownership, equity interest, patient/licensing arrangements, etc) that might pose a conflict of interest in connection with the submitted article.

All ICMJE Conflict of Interest Forms for authors and Clinical Orthopaedics and Related Research ${ }^{\circledR}$ editors and board members are on file with the publication and can be viewed on request.

Each author certifies that his or her institution approved the human protocol for this investigation, that all investigations were conducted in conformity with ethical principles of research, and that informed consent for participation in the study was obtained.

T. Terjesen ( $\square)$, J. Horn

Department of Orthopaedics, Oslo University Hospital,

Rikshospitalet, University of Oslo, Postboks 4950, Nydalen, 0424 Oslo, Norway

e-mail: terje.terjesen@ rikshospitalet.no patients (51 girls [91\%]; 74 hips) primarily treated during the period 1958 to 1962 . Group B comprised 38 patients (36 girls [95\%]; 40 hips) treated during the period 1996 to 2002. The mean age at the time of hip reduction was 20 months (SD 9.6) in Group A and 17 months (SD 11.9) in Group B. The mean time in skin traction had decreased from 35 days (SD 12.5) to 11 days (SD 5.7) over the years $(\mathrm{p}<0.001)$. Open reduction was performed in six of 74 hips (8\%) in Group A and 15 of 40 hips (37\%) in Group B $(\mathrm{p}<0.001)$. The immobilization time in the hip spica had decreased from 9 to 6 months $(\mathrm{p}<0.001)$. The indication for secondary procedures to correct residual dysplasia was center-edge angle $<20^{\circ}$ and was similar in both groups. A modified version of the radiographic classification of Severin was used to compare the results.

Results Secondary procedures to correct residual dysplasia were performed in 28 of 74 hips (38\%) in Group A and seven of 40 hips (18\%) in Group B (odds ratio [OR], $0.35 ; 95 \%$ confidence interval $[\mathrm{CI}], 0.14-0.89 ; \mathrm{p}=0.025)$ At skeletal maturity, the proportion of patients with satisfactory radiographic results (Severin Grades I/II) was larger in Group B (33 of 40 hips [82\%]) than in Group A (46 of 74 hips [62\%]; OR, 0.35; CI, 0.14-0.89; $\mathrm{p}=0.025$ ). Femoral head coverage, assessed as the center-edge angle, was greater in Group B than in Group A (mean $26^{\circ}$ versus $22^{\circ}$; CI, 0.8-7.9; $\mathrm{p}=0.016$ ). There was no difference in the proportion of avascular necrosis of the femoral head (seven of 74 hips [9\%] in Group A and five of 40 [13\%] in Group $\mathrm{B}$; OR, 1.4; CI, 0.4-4.6; $\mathrm{p}=0.614$ ).

Conclusions The move away from prolonged use of skin traction and toward more frequent open reduction for children with a late diagnosis of DDH appears to result in fewer secondary procedures and a better radiographic appearance of the hip at skeletal maturity. Based on the present results, we cannot conclude whether preliminary 
traction is needed; this question should be evaluated in future long-term studies with a prospective, randomized design.

Level of Evidence Level III, therapeutic study.

\section{Introduction}

The aims of treatment of late-detected congenital or developmental hip dislocation (DDH) are to obtain concentric hip reduction, maintain satisfactory femoral head coverage during growth, and avoid complications. Despite a vast number of clinical studies, no consensus has been reached on the optimal management to obtain these goals. Whereas closed reduction was common in the past [13, 27], open reduction has become more frequently used during the recent decades [2, 14, 21]. Both closed and open reduction has been supplemented with additional procedures like femoral and pelvic osteotomies, either at the time of hip reduction or at a later stage.

Many studies have been published on short-term results of treatment for late-detected DDH but there are relatively few studies in which the patients have been followed to skeletal maturity. Such long followup is necessary because there is a trend to deterioration during the last part of the growing period [6] and because growth disturbances of the proximal femur may not be evident until adolescence [8, 14].

There is a lack of studies where different treatment concepts have been compared. Because the radiographs and clinical data on patients treated in our department several decades ago were still available, we were able to perform such a study. Around 1960 most children in Norway with late-detected DDH were treated in our department. The treatment was quite uniform with a relatively long period of traction to obtain gradual closed reduction and quite long immobilization in a hip spica. A study of this method with 50 years followup recently has been published [28]. Fifty-four of 71 patients (76\%) were also part of the present study (Group A). The added information given in the present report is that the radiographic results during childhood and at skeletal maturity were analyzed in more detail and used for comparison with our recently treated patients (Group B). This enabled us to compare the patients treated around 1960 with those treated 40 years later to evaluate whether the changes in treatment concepts have been of benefit to the patients.

The aims of this study were to see whether decreasing use of skin traction and instead a more aggressive approach to open reduction resulted in (1) reduced use of secondary procedures; (2) improved radiographic appearance of the hips at long-term followup; and (3) changes in the proportion of patients developing avascular necrosis (AVN).

\section{Patients and Methods}

Two groups of patients with late-detected DDH (defined as patient age $>3$ months at treatment start) were compared retrospectively. Patients were included if they met the following criteria: no associated anomaly, no neuromuscular disorder, no previous treatment in other hospitals, patient age older than 3 months and younger than 5 years at the initiation of treatment, and available radiographs from the time of diagnosis to skeletal maturity. Patients with acetabular dysplasia only or slight subluxation were not included. The study was approved by the hospital's privacy and data protection officer (ref. 2014/14357).

Group A consisted of patients recruited through a search of the diagnosis card index of patients with late-detected DDH primarily treated during the period 1958 to 1962 . Seventy-five patients were identified, of whom 19 were excluded for the following reasons: 13 lacked radiographic followup at skeletal maturity, two had died before skeletal maturity, three lacked primary radiographs (two) or a case record (one), and one was $>5$ years at treatment start. Thus, Group A included 56 of 75 patients (75\%), who were all followed to skeletal maturity. There were 51 girls (91\%) and five boys with a mean age of 17 months (SD 8.9; range, 2-48 months) at the time of diagnosis.

Group B comprised all the 39 patients who were treated for late-detected DDH during the period 1996 to 2002. One patient was excluded because the followup routines were not followed. Thus, Group B consisted of 38 of 39 patients who were all followed prospectively during childhood. They were 36 girls (95\%) and two boys with a mean age of 14 months (8.9; range, 2-47 months) at diagnosis.

Patients in Group A had bilateral DDH more often than those in Group B (Table 1). Total dislocation occurred in $85 \%$ and subluxation in $15 \%$ of the hips in both groups. There were no differences in radiographic parameters between Groups A and B at the time of diagnosis (Table 2).

During the period the patients in Group A were treated, longitudinal skin traction to obtain gradual closed reduction was the main method for late-detected DDH in our department. Details of the rather strict traction regime have been explained earlier [28]. The aim was to achieve reduction during the traction period; no formal "reduction maneuver" was performed. However, a long traction period is inconvenient for the child and the family and requires special skill from the nursing staff to avoid complications like skin lesions and failure of the child to thrive. This plus reduction of the number of beds in our unit were the reasons for reduced traction time in Group B. Then, the aim of traction was no longer to obtain reduction, but to stretch the soft tissues. The subsequent reduction was performed under general anesthesia. If closed reduction was not obtained, open reduction was performed under the same anesthesia. 
Table 1. Clinical data according to patient groups (Group A: patients treated 1958-1962, Group B: patients treated 1996-2002)

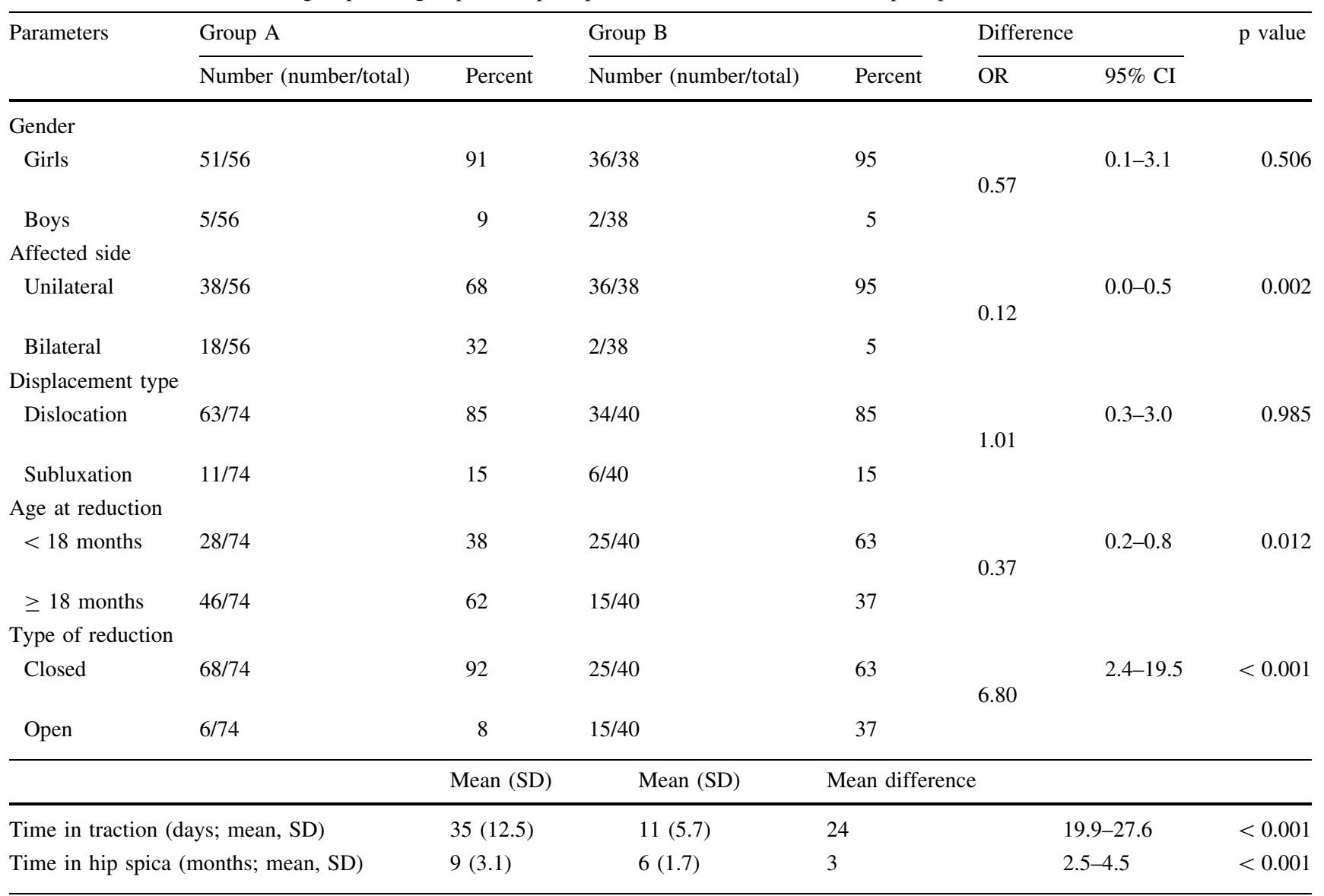

$\mathrm{OR}=$ odds ratio; $\mathrm{CI}=$ confidence interval.

Table 2. Radiographic parameters at diagnosis and at short- and medium-term followup according to treatment group

\begin{tabular}{|c|c|c|c|c|c|c|c|c|c|}
\hline \multirow[t]{2}{*}{ Time } & \multicolumn{2}{|c|}{ Radiographic parameter } & \multicolumn{2}{|c|}{ Group A } & \multicolumn{2}{|c|}{ Group B } & \multicolumn{2}{|c|}{ Difference } & \multirow[t]{2}{*}{$\mathrm{p}$ value } \\
\hline & & & Mean & SD & Mean & SD & Mean & $95 \% \mathrm{CI}$ & \\
\hline \multirow[t]{4}{*}{ Diagnosis } & \multicolumn{2}{|c|}{ Acetabular index $\left(^{\circ}\right)$} & 36 & 3.6 & 37 & 5.3 & -1 & -2.9 to 0.9 & 0.322 \\
\hline & \multicolumn{2}{|c|}{ Migration percentage } & 95 & 13.1 & 95 & 14.2 & 0 & -6.7 to 6.3 & 0.953 \\
\hline & \multicolumn{2}{|c|}{ Lateral metaphyseal distance (mm) } & 31 & 4.9 & 29 & 5.7 & 2 & -0.5 to 3.8 & 0.126 \\
\hline & \multicolumn{2}{|c|}{ Vertical metaphyseal distance $(\mathrm{mm})$} & -2 & 5.9 & -1 & 5.0 & -1 & -3.2 to 1.4 & 0.446 \\
\hline \multirow[t]{2}{*}{1 year postoperative } & \multicolumn{2}{|c|}{ Acetabular index $\left({ }^{\circ}\right)$} & 22 & 4.6 & 24 & 4.7 & -2 & -4.0 to -0.3 & 0.021 \\
\hline & \multicolumn{2}{|c|}{ Migration percentage } & 3 & 7.3 & 11 & 11.7 & -8 & -11.3 to -4.1 & $<0.001$ \\
\hline \multirow[t]{3}{*}{3 years postoperative } & \multicolumn{2}{|c|}{ Acetabular index $\left({ }^{\circ}\right)$} & 19 & 5.0 & 21 & 5.0 & -2 & -3.5 to 0.5 & 0.130 \\
\hline & \multicolumn{2}{|c|}{ Migration percentage } & 15 & 11.2 & 17 & 10.3 & -2 & -5.9 to 2.7 & 0.458 \\
\hline & \multicolumn{2}{|l|}{$\mathrm{CE}$ angle $\left(^{\circ}\right)$} & 21 & 7.6 & 20 & 7.4 & 1 & $-2.1-3.9$ & 0.552 \\
\hline \multirow[t]{3}{*}{ Age $8-10$ years } & \multicolumn{2}{|c|}{ Acetabular index $\left({ }^{\circ}\right)$} & 18 & 5.9 & 15 & 5.3 & 3 & $0.4-4.9$ & 0.022 \\
\hline & \multicolumn{2}{|c|}{ Migration percentage (\%) } & 22 & 11.2 & 16 & 8.5 & 6 & $1.6-9.7$ & 0.007 \\
\hline & \multicolumn{2}{|l|}{ CE angle $\left(^{\circ}\right)$} & 20 & 7.5 & 24 & 7.9 & -4 & -6.5 to -0.4 & 0.025 \\
\hline Severin grade & Number of hips & Percent & \multicolumn{2}{|c|}{ Number of hips } & \multicolumn{2}{|c|}{ Percent } & OR & & \\
\hline I/II & $44 / 74$ & 59 & \multicolumn{2}{|l|}{$27 / 39$} & \multicolumn{2}{|c|}{69} & 0.65 & $0.3-1.5$ & 0.307 \\
\hline III/IV & $30 / 74$ & 41 & \multicolumn{2}{|l|}{$12 / 39$} & \multicolumn{2}{|c|}{31} & & & \\
\hline
\end{tabular}

$\mathrm{CI}=$ confidence interval $\mathrm{CE}$ angle $=$ center-edge angle; $\mathrm{OR}=$ odds ratio. 
The mean time in skin traction had decreased markedly from 35 days (SD 12.5; range, 16-76 days) in Group A to 11 days (SD 5.7; range, 0-28 days) in Group B (Table 1).

The mean age at the time of hip reduction was 20 months (SD 9.6; range, 4-52 months) in Group A and 17 months (SD 11.8; range, 4-50 months) in Group B (mean difference 3.7; confidence interval [CI], -0.4 to $7.7 ; \mathrm{p}=0.076$ ). Closed reduction was achieved in 70 hips $(95 \%)$ in Group A and 28 hips $(70 \%)$ in Group B $(\mathrm{p}<0.001)$. Open reduction was necessary in the remaining using an anterior approach with a short transverse incision one fingerbreath distal to the anterosuperior iliac spine, excision of ligamentum teres, and release of the transverse acetabular ligament. Early redislocation (in the first hip spica) occurred in three hips in Group A (all had had closed reduction) and four hips in Group B (three after closed and one after open reduction) and was treated with closed rereduction in one hip and open reduction in six hips. Thus, the number of open reductions increased to six of 74 hips (8\%) in Group A and 15 of 40 hips (37\%) in Group B (odds ratio [OR], 6.8; CI, 2.4-19.5; p $<0.001$ ). The three oldest patients in Group B (age 42-50 months) had no preliminary traction and underwent open reduction, femoral shortening osteotomy, and a Dega-type incomplete transiliac pelvic osteotomy [10].

The mean immobilization time in a hip spica (Table 1) had decreased markedly, from 9 months (SD 3.1; range, 120 months) in Group A to 6 months (SD 1.7; range, 2-9 months) in Group B (mean difference 3.5; CI, 2.5-4.5; $<<$ 0.001 ). Position of hips in the spica was slight flexion and $40^{\circ}$ to $60^{\circ}$ abduction in Group A and approximately $90^{\circ}$ flexion and $40^{\circ}$ to $50^{\circ}$ abduction in Group B. The spica was changed every 3 months.

During the period the patients in Group A were treated, it was common to perform an early derotation femoral osteotomy as part of the primary treatment, because there was a belief that increased femoral anteversion was the most common cause of recurrent subluxation and that early derotation osteotomy would secure more concentric position of the hip [24]. Derotation was performed within 3 years from the time of hip reduction in 33 patients and 43 hips (58\%). A transverse osteotomy just distal to the lesser trochanter was carried out. The distal fragment was rotated externally $40^{\circ}$ to $60^{\circ}$ and fixation was secured with a fourhole straight steel plate. No early derotation osteotomy was performed in Group B.

Residual hip dysplasia or subluxation occurred in 30 of 74 hips (41\%) in Group A and nine of 40 hips (23\%) in Group B $(p=0.143)$. The indication for late corrective surgery was similar in both groups (center-edge angle under $20^{\circ}$ ) and did not change substantially over both study periods.

\section{Radiographic Evaluation}

AP radiographs of the pelvis were taken with the child in the supine position. Care was taken to position the child with the legs parallel and to avoid rotation of the pelvis and hips. For assessment of radiographic development of the hips, these radiographs were used: the primary one and those taken 1 and 3 years after hip reduction, at age 8 to 10 years, and at skeletal maturity. The last followup was at a mean patient age of 18.8 years (SD 3.7; range, 15-29 years) in Group A and 14.4 years (SD 1.5; range, 12-17 years) in Group B $(p<0.001)$. The radiographic assessment and measurements were performed by the senior author (TT) who has long experience with such evaluations. This author participated in the treatment of patients in Group B but not in Group A.

The acetabular index (AI) was measured according to Kleinberg and Lieberman [12]. The proximal and lateral displacement of the femoral metaphysis was measured using the lateral edge of the proximal femoral metaphysis and the medial edge of the acetabular roof as landmarks [27]. The center-edge (CE) angle of Wiberg [29] was included from 3 years after reduction. The migration percentage was measured according to Reimers [18]. When migration is $33 \%$ to $89 \%$, the hip is subluxated and $90 \%$ or more means complete dislocation. Assessment of AVN of the femoral head was performed by one of the authors (TT) according to Kalamchi and MacEwen [8], but only Groups II to IV were regarded as true AVN.

The radiographic outcome was evaluated with a modification of the classification of Severin [22]. We used the same limit for $\mathrm{CE}$ angle in children younger than 14 years as in older patients. Severin Grades I and II hips have CE angles of $20^{\circ}$ or above. Severin Grade III is acetabular dysplasia with CE angle under $20^{\circ}$. Severin Grade IV is subluxation with $\mathrm{CE}$ angle less than $10^{\circ}$, migration percentage above $33 \%$ plus a broken Shenton line. Hips with $\mathrm{CE}$ angle $20^{\circ}$ or higher had a satisfactory radiographic outcome and those with $\mathrm{CE}$ angle $<20^{\circ}$ were termed unsatisfactory.

\section{Statistics}

SPSS software, Version 21 (IBM, Armonk, NY, USA), was used for statistical analysis. Categorical data were analyzed with Pearson's chi square test and continuous variables with the t-test for independent samples. All tests were twosided. Differences were considered significant if the $p$ value was $<0.05$. 


\section{Results}

\section{Surgical Correction of Residual Hip Dysplasia}

Residual hip dysplasia or subluxation occurred in 30 hips $(41 \%)$ in Group A and nine hips $(23 \%)$ in Group B (p = 0.143 ). Corrective surgery was performed less frequently in Group B than in Group A (18\% versus 38\%; OR, 0.35; CI, $0.1-0.9 ; \mathrm{p}=0.025)$. There was a marked difference in operative procedures (Table 3). Isolated femoral osteotomy (varus and derotation) and isolated Spitzy shelf operation [25] were most often performed in Group A, whereas combined femoral and acetabular osteotomies were the most common operations in Group B (Fig. 1). The acetabular osteotomies were done with the Salter technique [19] in Group A and the Dega technique [10] in Group B. Mean patient age at operation was lower in Group B than in Group A (7 years [SD 4.5] versus 11 years [SD 4.5]; mean difference 3.4; $\mathrm{p}=0.079)$. Preoperative $\mathrm{CE}$ angle did not differ between groups $\mathrm{A}$ and $\mathrm{B}\left(10^{\circ}[\mathrm{SD} 5.4]\right.$ versus $9^{\circ}$ [SD 3.9]; mean difference $1.3 ; \mathrm{CI},-3.2$ to $5.7 ; \mathrm{p}=0.563$ ). The mean improvement of $\mathrm{CE}$ angle 1 year postoperatively was better in Group B $\left(21^{\circ}\right.$ [SD 10.7] versus $10^{\circ}$ [SD 8.3]; mean difference 11; CI, 3.2-18.6; $\mathrm{p}=0.007$ ) and Group B had more often a satisfactory short-term effect, defined as an improvement in CE angle of $10^{\circ}$ or more 1 year postoperatively (Table 3 ).

Because of an unsatisfactory result, a second operation was performed in six hips (four femoral osteotomies and two acetabular shelf operations) in Group A at a mean patient age of 12.8 years with good short-term results in two hips. A third operation (combined acetabular shelf and femoral osteotomy) was performed because of relapse of subluxation in one hip with a good effect. Only one hip was operated on a second time in Group B (periacetabular osteotomy at patient age 14 years).

Radiographic Results During Childhood and at Skeletal Maturity

The mean AI was markedly increased $\left(36^{\circ}-37^{\circ}\right)$ and showed a satisfactory reduction of $13^{\circ}$ to $14^{\circ}$ during the first year in both groups. At the 1-year followup the AI and migration percentage were larger in Group B than in Group $\mathrm{A}$; at the 3-year followup, there were no differences, and at age 8 to 10 years, AI and migration percentage were smaller in Group B (Table 2). The mean CE angle was $19^{\circ}$ to $20^{\circ}$ at the 3-year followup in both groups and larger in Group B at age 8 to 10 years $\left(24^{\circ}\right.$ versus $\left.20^{\circ} ; \mathrm{p}=0.025\right)$. This means that femoral head coverage was better in Group $\mathrm{B}$ at age 8 to 10 years.

At skeletal maturity, femoral head coverage was better in Group B with lower migration percentage and larger CE angle (Table 4). The rate of hips with satisfactory outcome (Severin Grades I/II) was greater in Group B than in Group A ( $82 \%$ versus $62 \%$; OR, 0.35 ; CI, $0.1-0.9 ; p=0.025)$. In Group A, there was no difference in Severin grades between unilateral and bilateral cases $(p=0.254)$.

In Group B, open reduction was not performed in any patients younger than 12 months of age, but was necessary in $65 \%$ of the patients aged $\geq 12$ months (Table 5). The radiographic outcome was satisfactory (Severin Grade I/II) in 14 of 15 hips (93\%). Although the numbers of hips in the different age groups were small, the results showed no deterioration with increasing age at reduction. In patients $\geq$ 12 months the proportion of Severin Grade I/II hips was larger after open reduction than after closed reduction in

Table 3. Frequency and short-term results of late surgical correction of residual hip dysplasia and subluxation

\begin{tabular}{|c|c|c|c|c|c|c|c|}
\hline \multirow[t]{2}{*}{ Parameters } & \multicolumn{2}{|l|}{ Group A } & \multicolumn{2}{|l|}{ Group B } & \multicolumn{2}{|c|}{ Difference } & \multirow[t]{2}{*}{$\mathrm{p}$ value } \\
\hline & Number (number/total) & Percent & Number (number/total) & Percent & OR & $95 \% \mathrm{CI}$ & \\
\hline \multicolumn{8}{|l|}{ Late surgery } \\
\hline No & $46 / 74$ & 62 & $33 / 40$ & 82 & 0.35 & $0.1-0.9$ & 0.025 \\
\hline Surgery & $28 / 74$ & 38 & $7 / 40$ & 18 & & & \\
\hline \multicolumn{8}{|l|}{ Type of operation } \\
\hline Femoral osteotomy & $12 / 28$ & 43 & $1 / 7$ & 14 & & & 0.001 \\
\hline Spitzy shelf operation & $12 / 28$ & 43 & $0 / 7$ & 0 & & & \\
\hline Salter acetabular osteotomy & $4 / 28$ & 14 & $0 / 7$ & 0 & & & \\
\hline Acetabular osteotomy and femoral osteotomy & $0 / 28$ & 0 & $6 / 7 *$ & 86 & & & \\
\hline \multicolumn{8}{|l|}{ Results of surgery at 1 year postoperative } \\
\hline Satisfactory & $10 / 28$ & 36 & $7 / 7$ & 100 & 0.59 & $0.4-0.9$ & 0.002 \\
\hline Unsatisfactory & $18 / 28$ & 64 & $0 / 7$ & 0 & & & \\
\hline
\end{tabular}

* Four Dega-type acetabular osteotomies and two Spitzy shelf operations; OR = odds ratio; CI = confidence interval. 

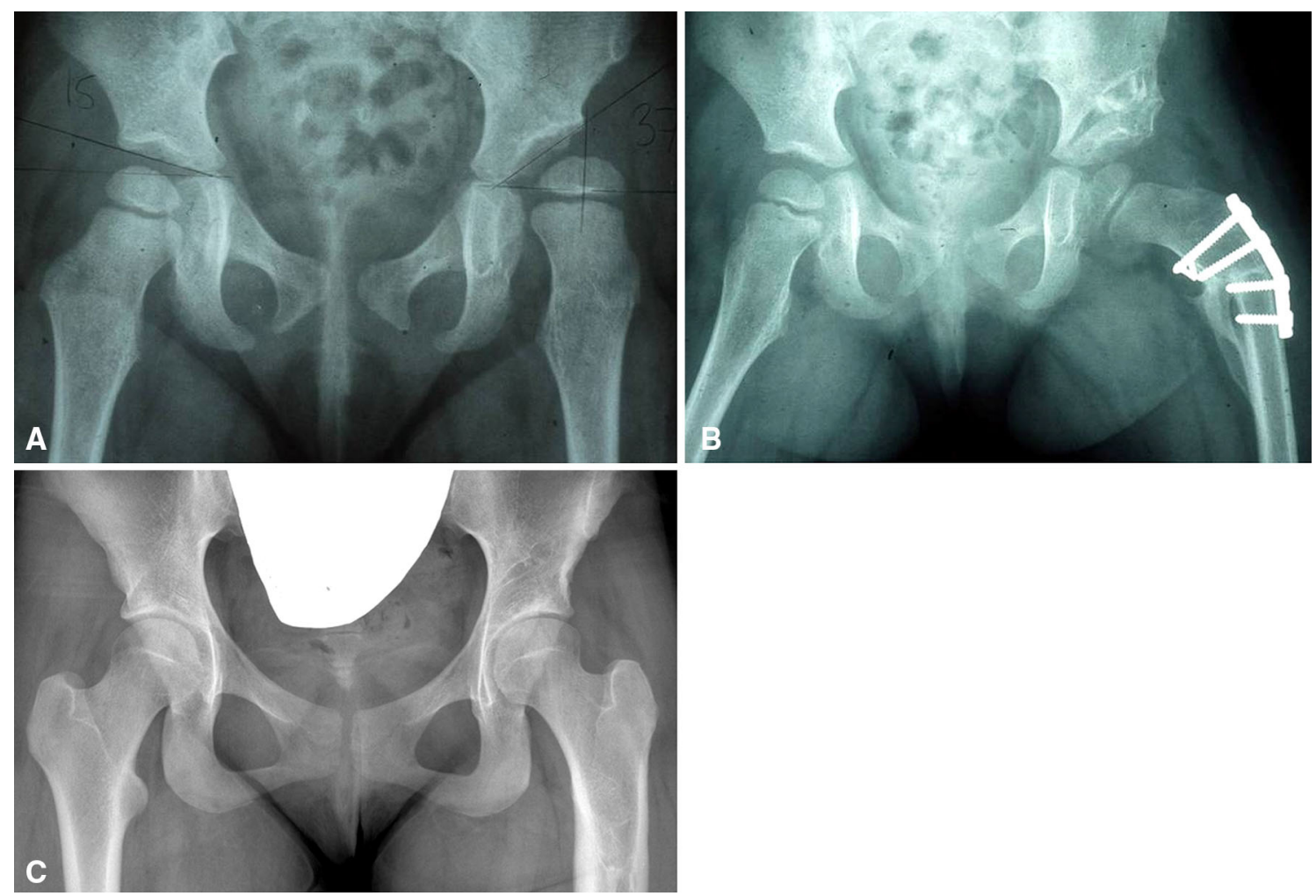

Fig. 1A-C Radiographs show the hips of a girl (Group B) who underwent corrective surgery because of residual subluxation. Open reduction had been performed at an age of 17 months. (A) Radiograph 1.5 years after reduction shows subluxation of the left hip (MP 48\%). (B) Radiograph 2 months after Dega pelvic osteotomy of the left hip shows good correction. Shortening osteotomy of the femur was also performed and the cortical bone fragment removed from the femur was placed in the open wedge of the pelvic osteotomy. (C) Radiograph at age 14 years shows adequate femoral head coverage with $\mathrm{CE}$ angle $31^{\circ}$.

Table 4. Radiographic results at skeletal maturity according to treatment group and age at reduction

\begin{tabular}{|c|c|c|c|c|c|c|c|c|c|c|c|c|}
\hline \multirow{2}{*}{\multicolumn{2}{|c|}{ Age at reduction }} & \multirow{2}{*}{\multicolumn{2}{|c|}{ Radiographic parameter }} & \multicolumn{2}{|l|}{ Group A } & \multicolumn{2}{|c|}{ Group B } & \multicolumn{3}{|c|}{ Difference } & & \multirow[t]{2}{*}{$\mathrm{p}$ value } \\
\hline & & & & Mean & SD & Mean & SD & Mean & $95 \%$ & & & \\
\hline \multirow[t]{3}{*}{ All hips } & & \multirow{2}{*}{\multicolumn{2}{|c|}{$\begin{array}{l}\text { Migration percentage }(\%) \\
\mathrm{CE} \text { angle }\left({ }^{\circ}\right)\end{array}$}} & 25 & 8.7 & 20 & 8.6 & 5 & \multirow{2}{*}{\multicolumn{3}{|c|}{$\begin{array}{l}1.7-8.5 \\
-7.9 \text { to }-0.8\end{array}$}} & 0.004 \\
\hline & & & & 22 & 8.9 & 26 & 8.9 & -4 & & & & 0.016 \\
\hline & & & \multicolumn{2}{|c|}{ Number of hips (number/total) } & Percent & \multicolumn{3}{|c|}{ Number of hips (number/total) } & Percent & OR & & \\
\hline \multirow[t]{2}{*}{ All hips } & Sev & Grade I/II & $46 / 74$ & & 62 & $33 / 40$ & & & 82 & 0.35 & $0.1-0.9$ & 0.025 \\
\hline & Sev & Grade III/IV & $28 / 74$ & & 38 & $7 / 40$ & & & 18 & & & \\
\hline \multirow[t]{2}{*}{$<18$ months } & Sev & Grade I/II & $22 / 28$ & & 79 & $21 / 25$ & & & 84 & 0.70 & $0.2-2.8$ & 0.614 \\
\hline & Sev & Grade III/IV & $6 / 28$ & & 21 & $4 / 25$ & & & 16 & & & \\
\hline \multirow[t]{2}{*}{$\geq 18$ months } & Sev & Grade I/II & $24 / 46$ & & 52 & $12 / 15$ & & & 80 & 0.27 & $0.1-1.1$ & 0.057 \\
\hline & $\mathrm{Sev}$ & Grade III/IV & $22 / 46$ & & 48 & $3 / 15$ & & & 20 & & & \\
\hline
\end{tabular}

$\mathrm{CI}=$ confidence interval; $\mathrm{CE}$ angle $=$ center-edge angle; $\mathrm{OR}=$ odds ratio.

Group B (93\% versus 50\%; OR, 0.07; CI, 0.01-0.8; $\mathrm{p}=$ $0.016)$.

Age 18 months or older at reduction was a risk factor for unsatisfactory results (Severin Grades III/IV) at skeletal maturity in Group A (Table 6) but not in patient Group B. Residual hip dysplasia during the followup period was associated with unsatisfactory results at skeletal maturity. 
Table 5. Frequency of open reduction and radiographic outcome at skeletal maturity in Group B (number and percent of hips)

\begin{tabular}{lllll}
\hline Age at reduction (months) & Open reduction & & \multicolumn{2}{l}{ Radiographic outcome; Severin Grade I/II } \\
\cline { 2 - 2 } & Number of hips (number/total) & Percent & & Number of hips (number/total) \\
\hline $0-11$ & $0 / 17$ & 0 & & \\
$12-17$ & $5 / 8$ & 63 & $5 / 5$ \\
$18-23$ & $3 / 6$ & 50 & $3 / 3$ & 100 \\
$\geq 24$ & $7 / 9$ & 78 & $6 / 7$ \\
\hline
\end{tabular}

Table 6. Prognostic factors for radiographic outcome at skeletal maturity (given as number of hips) in Groups A and B

\begin{tabular}{|c|c|c|c|c|c|c|c|c|c|c|}
\hline \multirow[t]{3}{*}{ Parameters } & \multicolumn{4}{|c|}{ Group A } & \multirow[t]{3}{*}{$\mathrm{p}$ value } & \multicolumn{4}{|c|}{ Group B } & \multirow[t]{3}{*}{$\mathrm{p}$ value } \\
\hline & \multicolumn{2}{|c|}{ Severin grade } & \multicolumn{2}{|c|}{ Difference } & & \multicolumn{2}{|c|}{ Severin grade } & \multicolumn{2}{|c|}{ Difference } & \\
\hline & $\mathrm{I} / \mathrm{II}$ & III/IV & OR & $95 \% \mathrm{CI}$ & & $\mathrm{I} / \mathrm{II}$ & III/IV & OR & $95 \% \mathrm{CI}$ & \\
\hline Age $<18$ months & $22 / 28$ & $6 / 28$ & 3.3 & $1.2-9.8$ & 0.023 & $21 / 25$ & $4 / 25$ & 1.3 & $0.3-6.9$ & 0.747 \\
\hline Age $\geq 18$ months & $24 / 46$ & $22 / 46$ & & & & $12 / 15$ & $3 / 15$ & & & \\
\hline AVN & $0 / 7$ & $7 / 7$ & 0.3 & $0.2-0.5$ & $<0.001$ & $4 / 5$ & $1 / 5$ & 1.2 & $0.1-12.8$ & 0.875 \\
\hline No AVN & $46 / 67$ & $21 / 67$ & & & & $29 / 35$ & $6 / 35$ & & & \\
\hline No residual dysplasia & $33 / 44$ & $11 / 44$ & & & 0.014 & $28 / 31$ & $3 / 31$ & & & 0.050 \\
\hline Residual dysplasia & $6 / 11$ & $5 / 11$ & & & & $2 / 4$ & $2 / 4$ & & & \\
\hline Subluxation & $7 / 19$ & $12 / 19$ & & & & $3 / 5$ & $2 / 5$ & & & \\
\hline
\end{tabular}

$\mathrm{OR}=$ odds ratio; $\mathrm{CI}=$ confidence interval; $\mathrm{AVN}$ = avascular necrosis of the femoral head.

\section{Proportion of Patients Developing Avascular Necrosis}

AVN of the femoral head occurred in five patients (seven hips [9\%]) in Group A and five patients (five hips [13\%]) in Group B ( $\mathrm{p}=0.614)$. The distribution of AVN was Group II in three hips and Group III in four hips in Group A. The corresponding numbers in Group B were four and one. AVN was seen more frequently after open reduction (four hips [27\%]) than after closed reduction (one hip [4\%]) in Group B $(p=0.036)$. AVN was a risk factor for unsatisfactory results (defined as a Severin grade of III/IV) in Group A but not in Group B (Table 6). The reason was that four of five hips with AVN in Group B were Grade II [8] and these four hips had a satisfactory outcome (Fig. 2).

\section{Discussion}

Late-detected DDH can be a difficult condition to treat. The aims are restoration of normal hip anatomy and avoidance of iatrogenic complications (AVN). There is no consensus on which method is the most appropriate to obtain these goals. To throw light on this problem, studies with long followup and studies with comparison of different treatment concepts are needed. We recently published a study with 50 years followup of traction treatment to obtain gradual closed reduction [28]. Most of these patients were used in the present study and their results at skeletal maturity were compared with those of our recently treated patients. Over the 50-year period of this study, our practice pattern moved away from lengthy periods of skin traction, and we used open reduction more liberally. These changes resulted in improved femoral head coverage and better radiographic results according to the Severin classification at skeletal maturity, less frequent use of secondary procedures to correct residual dysplasia, and no apparent increase in the risk of AVN.

There were some limitations of the present study. The age at reduction was some months higher in Group A than in Group B; we therefore analyzed results according to age at reduction. The followup period was somewhat shorter in Group B and some of the patients had not reached skeletal maturity. However, because all were older than 12 years, the radiographic outcome would hardly change with longer followup. The present outcome measure was radiographic only. We consider radiographic results more important than clinical results during childhood, because the patients rarely have pain or other complaints at this age. Besides, in our previous report of the patients in Group A [28] we found a strong association between the radiographic and clinical outcome (Harris hip score) at 50 years followup and also a significant association between the radiographic 

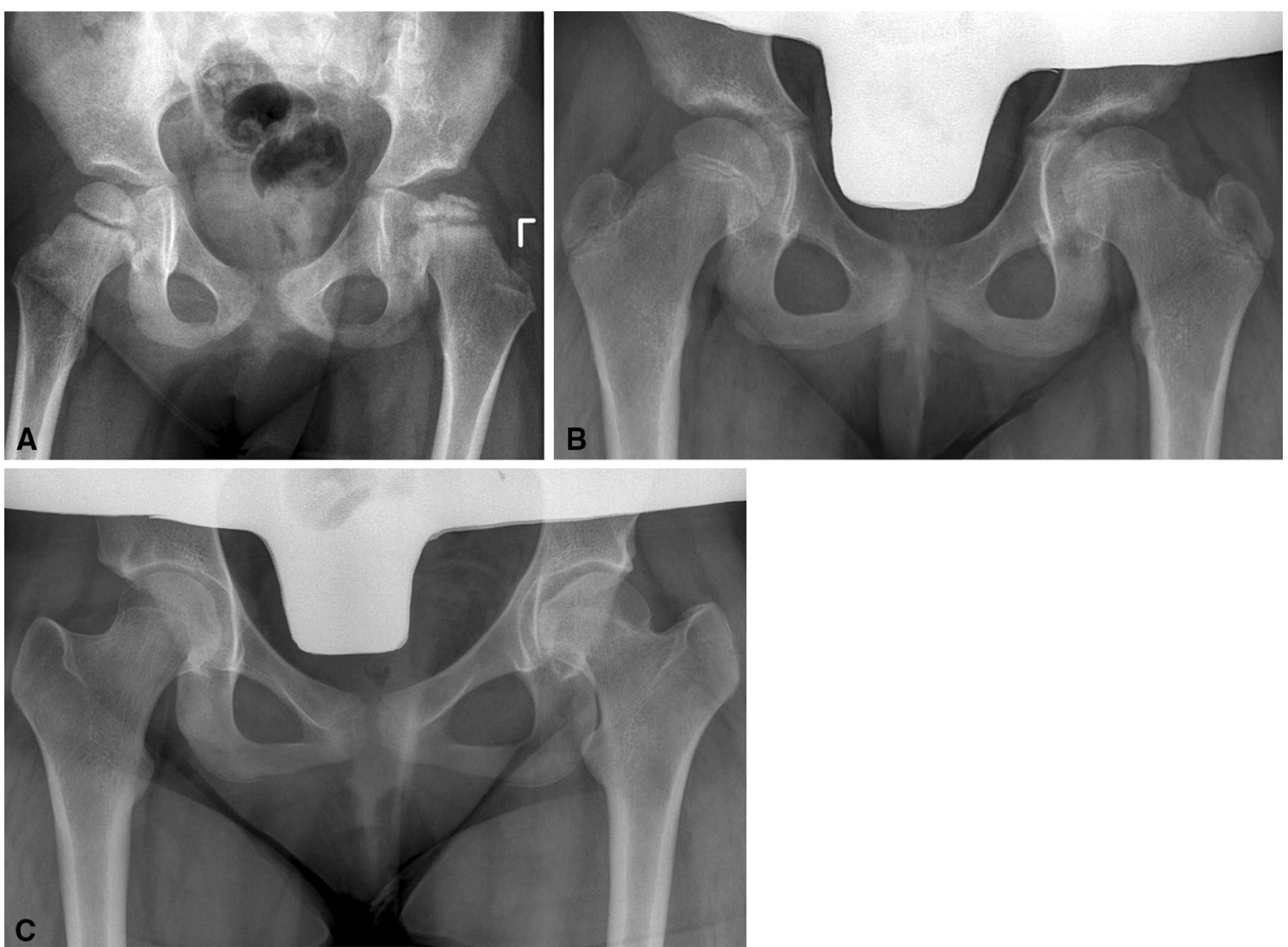

Fig. 2A-C Radiographs show the hips of a girl (Group B) who underwent closed reduction at an age of 6 months and developed AVN. (A) Radiograph at age 3 years shows AVN of the left hip. (B) At age 8 years, the AVN changes of the left femoral head have almost completely normalized. (C) Radiograph at age 13 years shows AVN Group II in the left hip with tilting of the femoral head into valgus (Severin Grade II).

results at skeletal maturity and those at 50 years followup. Thus, we think our outcome evaluation is representative not only for the present situation, but also for the development of the hips later during adulthood.

The proportion of corrective surgery for residual dysplasia was $18 \%$ in Group B and $38 \%$ in Group A. These rates are in accordance with rates from $20 \%$ to more than $60 \%$ in previous studies with no clear association with method of reduction (open or closed) [5, 9, 30-32]. The rate of secondary surgery can be reduced by the use of pelvic osteotomy at the time of reduction in patients older than 18 months [4, 15, 19], but this policy would, according to the present results, have implied unnecessary pelvic surgery in several of the hips. The types of surgical procedures differed between the patient groups. Around 1960 it was common to perform isolated femoral osteotomy or acetabular shelf operation. The results were satisfactory after acetabular shelf operations but less satisfactory after femoral osteotomy. Others have found that isolated femoral osteotomy is not effective in children $>8$ years and when the $\mathrm{AI}$ is $>25^{\circ}[11,30]$. In such cases, acetabular osteotomy is necessary to correct the acetabular dysplasia. This was the most common procedure in Group
B, usually combined with femoral osteotomy in cases of femoral valgus or increased anteversion. The more frequent use of combined osteotomies in Group B probably contributed to the better radiographic outcome in this group. In keeping with others [10], we prefer the Dega-type pelvic osteotomy, because it is more stable than the Salter type and does not require internal fixation.

The aim of traction in Group A was to achieve gradual reduction during a relatively long traction period. Closed reduction was obtained in more than $90 \%$ of the hips and the radiographic outcome at skeletal maturity was satisfactory (Severin Grade I/II) in almost two-thirds. This confirms the experience of other studies with long traction time (4-8 weeks) and gradual reduction $[9,15,17]$ where failure to obtain closed reduction in less than $10 \%$ of the hips and low rate of AVN $(<10 \%)$ were reported. Severin Grade I/II at skeletal maturity was obtained in $83 \%$ to $96 \%$ of the hips both when pelvic osteotomy had been performed at the time of reduction [15] and when pelvic osteotomy was performed later because of residual dysplasia $[9,17]$. We have found no previous studies that have compared this treatment concept and regimes with less traction time and more open reductions as we did in this study. 
The radiographic outcome of open reduction in Group B was good with Severin Grade I/II hips in 93\%. Our results are in accordance with previous studies of open reduction using the anterior approach with Severin Grade I/II in $96 \%$ of the hips at skeletal maturity [26] and in $92 \%$ at a mean followup of 6 years [2]. However, considerably worse results after open reduction were reported by Holman et al. [7] with only $33 \%$ Severin I/II hips after a mean followup of almost 30 years.

One argument for using traction is that it reduces the risk of AVN [20, 23]. However, other authors have found that traction did not influence the rate of AVN [3, 16]. We found no significant difference in the proportions of AVN between the two treatment groups. Our rate of AVN Groups II to IV was within the range of $5 \%$ to $43 \%$ in previous studies on open reduction $[1,7,14,26]$. AVN occurred more frequently after open reduction than after closed reduction in Group B, but most were Group II and had a good prognosis. In Group A, AVN was a risk factor for unsatisfactory results (Severin Grade III/IV) because of more severe degrees of AVN.

In conclusion, the move away from prolonged use of skin traction and toward more frequent open reduction for children with a late diagnosis of DDH resulted in fewer secondary procedures and a better radiographic appearance at skeletal maturity. Based on the present results, we cannot conclude whether preliminary traction is needed; this question should be evaluated in future long-term studies with a prospective, randomized design. Such randomized studies are also needed in children older than 18 months to evaluate whether pelvic osteotomy should be routinely performed at the time of reduction or be postponed and performed only in those who develop residual dysplasia.

\section{References}

1. Akilapa O. The medial approach open reduction for developmental dysplasia of the hip: do the long-term outcomes validate this approach. A systematic review of the literature. J Child Orthop. 2014;8:387-397.

2. Berkeley ME, Dickson JH, Cain TE, Donovan MM. Surgical therapy for congenital dislocation of the hip in patients who are twelve to thirty-six months old. J Bone Joint Surg Am. 1984;66:412-420.

3. Brougham DI, Broughton NS, Cole WG, Menelaus MB. Avascular necrosis following closed reduction of congenital dislocation of the hip. J Bone Joint Surg Br. 1990;72:557-562.

4. Chang $\mathrm{CH}$, Yang WE, Kao HK, Lee WC, Shih $\mathrm{CH}$, Kuo KN. Prognostic radiographic factors in developmental dysplasia of the hip following Salter osteotomy. J Pediatr Orthop B. 2015;24:31-34.

5. Forlin E, Choi IH, Guille JT, Bowen JR, Glutting J. Prognostic factors in congenital dislocation of the hip treated with closed reduction. J Bone Joint Surg Am. 1992;74:1140-1152.

6. Gibson PH, Benson MKD. Congenital dislocation of the hip. $J$ Bone Joint Surg Br. 1982;64:169-175.
7. Holman J, Carroll KL, Murray KA, MacLeod LM, Roach JW. Long-term follow-up of open reduction surgery for developmental dislocation of the hip. J Pediatr Orthop. 2012;32:121124.

8. Kalamchi A, MacEwen GD. Avascular necrosis following treatment of congenital dislocation of the hip. J Bone Joint Surg Am. 1980;62:876-888.

9. Kaneko H, Kitoh H, Mishima K, Matsushita M, Ishiguro N. Long-term outcome of gradual reduction using overhead traction for developmental dysplasia of the hip over 6 months of age. $J$ Pediatr Orthop. 2013;33:628-634.

10. Karlen JW, Skaggs DL, Ramachandran M, Kay RM. The Dega osteotomy: a versatile osteotomy in the treatment of developmental and neuromuscular hip pathology. J Pediatr Orthop. 2009;29;676-682.

11. Kasser JR, Bowen JR, MacEwen GD. Varus derotation osteotomy in the treatment of persistent dysplasia in congenital dysplasia of the hip. J Bone Joint Surg Am. 1985;67:195-202.

12. Kleinberg S, Lieberman HS. The acetabular index in infants in relation to congenital dislocation of the hip. Arch Surg. 1936;32:1049-1054.

13. Malvitz TA, Weinstein SL. Closed reduction for congenital dysplasia of the hip. Functional and radiographic results after an average of thirty years. J Bone Joint Surg Am. 1994;76:17771792.

14. Morcuende JA, Beyer MD, Dolan LA, Weinstein SL. Long-term outcome after open reduction through an anteromedial approach for congenital dislocation of the hip. J Bone Joint Surg Am. 1997;79:810-817.

15. Morin CM, Bisogno J, Kulkarni S, Morel G. Treatment of latepresenting developmental dislocation of the hip by progressive orthopaedic reduction and innominate osteotomy. Our results with more than 30 years of follow-up. J Child Orthop. 2011;5:251-260.

16. Quinn RH, Renshaw TS, DeLuca PA. Preliminary traction in the treatment of developmental dislocation of the hip. J Pediatr Orthop. 1994;14:636-642.

17. Rampal V, Sabourin M, Erdeneshoo E, Koureas G, Seringe R, Wicart P. Closed reduction with traction for developmental dysplasia of the hip in children aged between one and five years. J Bone Joint Surg Br. 2008;90:858-863.

18. Reimers J. The stability of the hip in children. Acta Orthop Scand. 1980;51(Suppl 84):4-91.

19. Salter RB. Innominate osteotomy in the treatment of congenital dislocation and subluxation of the hip. J Bone Joint Surg Br. 1961;43:518-539.

20. Salter RB, Kostuik J, Dallas S. Avascular necrosis of the femoral head as a complication of treatment for congenital dislocation of the hip in young children: a clinical and experimental investigation. Can J Surg. 1969;12:44-61.

21. Sankar WN, Young CR, Lin AG, Crow SA, Baldwin KD, Moseley CF. Risk factors for failure after open reduction for DDH: a matched cohort analysis. J Pediatr Orthop. 2011;31:232239.

22. Severin E. Contribution to the knowledge of congenital dislocation of the hip joint. Acta Chir Scand. 1941;84(Suppl 63):1-142.

23. Sibinski M, Murnaghan C, Synder M. The value of overhead traction in the closed management of DDH. Int Orthop. 2006;30:268-271.

24. Somerville EW, Scott JC. The direct approach to congenital dislocation of the hip. J Bone Joint Surg Br. 1957;39:623-640.

25. Spitzy H. [Acetabular shelf reconstruction] [in German]. $Z$ Orthop. 1924;43:284-294.

26. Szepesi K, Szücs G, Szeverenyi C, Csernatony Z. Long-term follow-up of DDH patients who underwent open reduction without a postoperative cast. J Pediatr Orthop B. 2013;22:85-90. 
27. Terjesen T, Halvorsen V. Long-term results after closed reduction of late-detected hip dislocation. 60 patients followed up to skeletal maturity. Acta Orthop. 2007;78:236-246.

28. Terjesen T, Horn J, Gunderson RB. Fifty-year follow-up of late-detected hip dislocation. J Bone Joint Surg Am. 2014;96: e28.1-9.

29. Wiberg G. Studies on dysplastic acetabula and congenital subluxation of the hip joint. Acta Chir Scand. 1939;83(Suppl 58): 7-135.
30. Williamson DM, Benson MKD. Late femoral osteotomy in congenital dislocation of the hip. J Bone Joint Surg Br. 1988;70:614-618.

31. Yamada N, Maeda S, Fujii G, Kita A, Funayama K, Kokubun S. Closed reduction of developmental dislocation of the hip by prolonged traction. J Bone Joint Surg Br. 2003;85:1173-1177.

32. Zionts LE, MacEwen GD. Treatment of congenital dislocation of the hip in children between the ages of one and three years. $J$ Bone Joint Surg Am. 1986;68:829-846. 